\title{
The intricate relationship between microtubules and their associated motor proteins during axon growth and maintenance
}

\author{
Andreas Prokop
}

\begin{abstract}
The hallmarks of neurons are their slender axons which represent the longest cellular processes of animals and which act as the cables that electrically wire the brain, and the brain to the body. Axons extend along reproducible paths during development and regeneration, and they have to be maintained for the lifetime of an organism. Both axon extension and maintenance essentially depend on the microtubule (MT) cytoskeleton. For this, MTs organize into parallel bundles that are established through extension at the leading axon tips within growth cones, and these bundles then form the architectural backbones, as well as the highways for axonal transport essential for supply and intracellular communication. Axon transport over these enormous distances takes days or even weeks and is a substantial logistical challenge. It is performed by kinesins and dynein/dynactin, which are molecular motors that form close functional links to the MTs they walk along. The intricate machinery which regulates MT dynamics, axonal transport and the motors is essential for nervous system development and function, and its investigation has huge potential to bring urgently required progress in understanding the causes of many developmental and degenerative brain disorders. During the last years new explanations for the highly specific properties of axonal MTs and for their close functional links to motor proteins have emerged, and it has become increasingly clear that motors play active roles also in regulating axonal MT networks. Here, I will provide an overview of these new developments.
\end{abstract}

Keywords: Axons, Growth cones, Cytoskeleton, Microtubules, Kinesins, Dynein, Transport, Brain disorders, Drosophila

\section{Review} Introduction

Axons are the longest cellular processes produced by animals. They conduct action potentials away from the neuronal cell body to pass them on to other cells at synapses (Figure 1) [1]. They are slender nerve cell extensions that electrically wire up the brain and establish the information highways that essentially underpin nervous system function. Axons can be up to a meter long in humans, especially those axons that are bundled into nerves of the body or into nerve tracts in the CNS (Figure 1). These remarkable cellular structures need to be fabricated during development and maintained for the lifetime of an animal, which in humans is for

\footnotetext{
Correspondence: Andreas.Prokop@manchester.ac.uk

Faculty of Life Sciences, Michael Smith Building, Oxford Road, Manchester M13 9PT, UK
}

decades. This long-lasting maintenance is an enormous logistical challenge where a tiny neuronal cell body sustains a cell compartment that is up to weeks away in terms of cargo transport duration - in relative dimensions comparable to the communication and supply lines which Alexander the Great or Hannibal faced when sustaining their war campaigns far away from their homelands [2]. In architectural terms, axons form not just a stable, cemented structure, but mature axons have the principal ability to undergo plastic reorganization underpinning learning and memory, and may re-grow after injury in order to regain lost control over body movement and behavioral abilities [3,4].

Clearly, axons are masterpieces of biology and their study has fascinated neurobiologists since they were first described in the second half of the 19th century [1]. Their study is important and will have important

\section{Biomed Central}

(c) 2013 Prokop; licensee BioMed Central Ltd. This is an Open Access article distributed under the terms of the Creative Commons Attribution License (http://creativecommons.org/licenses/by/2.0), which permits unrestricted use, distribution, and reproduction in any medium, provided the original work is properly cited. 


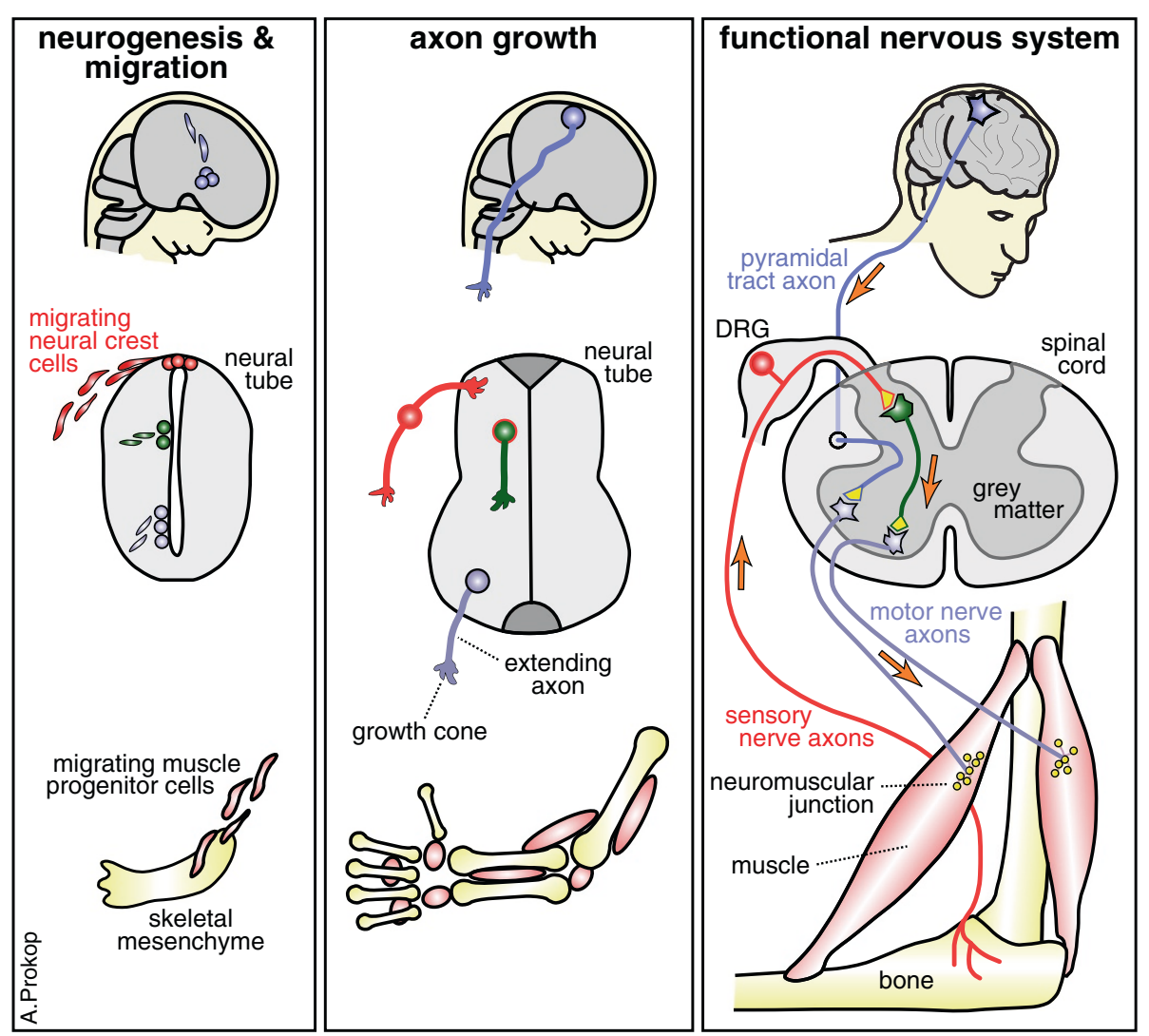

Figure 1 The growth and function of axons. The process of neurogenesis provides pools of neurons that migrate into their appropriate positions (left), that extend axons along reproducible paths (middle), and that are eventually wired up into the synaptic circuits which convey information across the nervous system, thus coordinating behavior (orange arrows: action potentials; yellow: presynaptic sides).

implications when considering the increasing social burden of brain disorders [5]. For example, axons undergo incremental loss during ageing, reaching $50 \%$ loss at 80 years [6], and understanding the reasons underlying this loss will address age-related brain disorders. Axons die back in many neurodegenerative diseases, and we will learn a lot from understanding whether this is cause or consequence of neuronal decay [7-9]. Failed re-growth of axons after spinal cord injury is an important cause of sustained paralysis, and learning ways to stimulate axonal re-growth and regeneration clearly addresses issues of life quality and economic burden [4].

To address such issues, it is pivotal to gain a fundamental understanding of the cell biology of neurons, in particular the role and regulation of axonal microtubules (MTs) which are the centerpieces of axons and have long been recognized as displaying unique features when compared to non-neuronal cells [10]. Important progress has been made over the last years in understanding these features, and it has become increasingly clear that there are close links between MTs, the process of axonal transport, and the motors which perform this function.
In this review, I will give a brief overview of the role and regulation of MTs in axons, describe their links to axonal transport and their intricate relationship with MT-associated motor proteins, the functions of which are not only transport-related.

\section{MTs in axons display specific properties and essentially drive axon growth}

MTs form the structural backbones of axons (Figure 2). They are stiff hollow tubes typically composed of 13 parallel protofilaments. These protofilaments are polar filamentous polymers of $\alpha$-/ $/ \beta$-tubulin heterodimers which frequently display posttranslational modifications including (poly-) glycylation and (poly-)glutamylation on the C-termini of both $\alpha$ - and $\beta$-tubulin, as well as $\alpha$-tubulin-specific acetylation and detyrosination (often followed by deglutamylation, resulting in $\Delta 2$-tubulin) $[11,12]$ (Figure 3). In contrast to MTs in non-neuronal cells, axonal MTs display a number of special features. First, axonal MTs range in length from just a few $\mu \mathrm{m}$ to many tenths of $\mu \mathrm{m}$ and they are arranged into evenly spaced prominent parallel bundles where most MTs point with their plus ends towards the 


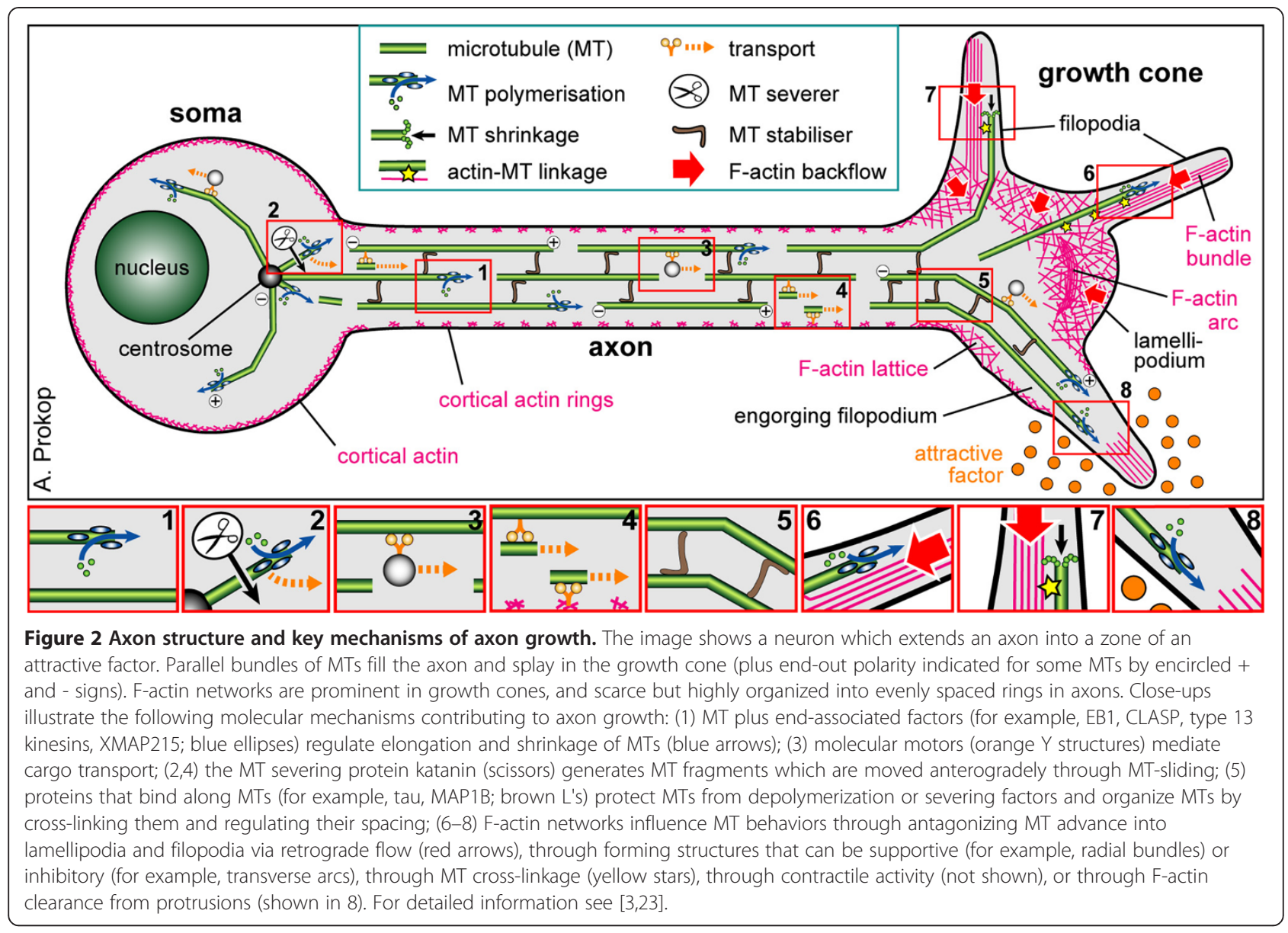

axon tip $[13,14]$. The mechanisms that bundle MTs are little understood, but are believed to involve MT-binding proteins (MTBPs) such as MAP1B or tau (Figure 2) $[15,16]$. Second, the nucleation of axonal MTs does not require the centrosome in the cell body (Figure 2), but can occur from diffuse sites in axons $[17,18]$. Third, ß-tubulin-associated guanosine triphosphate (GTP) is usually hydrolyzed to guanosine diphosphate (GDP) once incorporated into MTs (Figure 3), whereas axonal MTs maintain a high level of GTP-tubulin [19] with likely implications for their stability [20]. Fourth, sub-fractions of axonal MTs become polyaminated by transglutaminases (Figure 3 ) which renders these MTs stable to cold- and calcium-treatment [21]. Finally, axonal MTs of neurons are usually interwoven with intermediate filaments which are highly abundant in axons, are known to regulate the specific diameters of different axon classes, and have been associated with neurodegenerative processes [22].

Axon growth is essentially implemented through the extension of axonal MT bundles, and net positive polymerization of MTs is expected to contribute essentially to this growth (Figure 2). This notion is best illustrated by mutations in tubulin genes or tubulin chaperones such as tubulin folding cofactor E (Tbce) which negatively impact on MT polymerization, and which have been linked to neuro-developmental diseases including impaired axon growth [25,27]. There is some evidence for elongation within the axon shaft, which involves anterograde propulsion of long MTs and slow incremental forward flow of the entire MT mass toward the leading growth cone $[28,29]$. Such a finding is in principle consistent with the idea of de novo polymerization at disperse nucleation sites or at the plus ends of MTs along axon shafts [10,17]. Certainly this model needs further confirmation, but it could provide interesting explanations for how the tips of axonal MT bundles can push in growth cones during the process of protrusion, engorgement and consolidation which implement axon extension [23,30,31].

MTs polymerize (grow) and depolymerize (shrink) primarily at their plus ends, and these processes, as well as the directionality of MT extensions, are essentially regulated through tip interacting protein (+TIPs). +TIPs localize to MT plus ends primarily through interaction with end-binding proteins (EBs) which can directly bind to those MT plus ends that undergo 

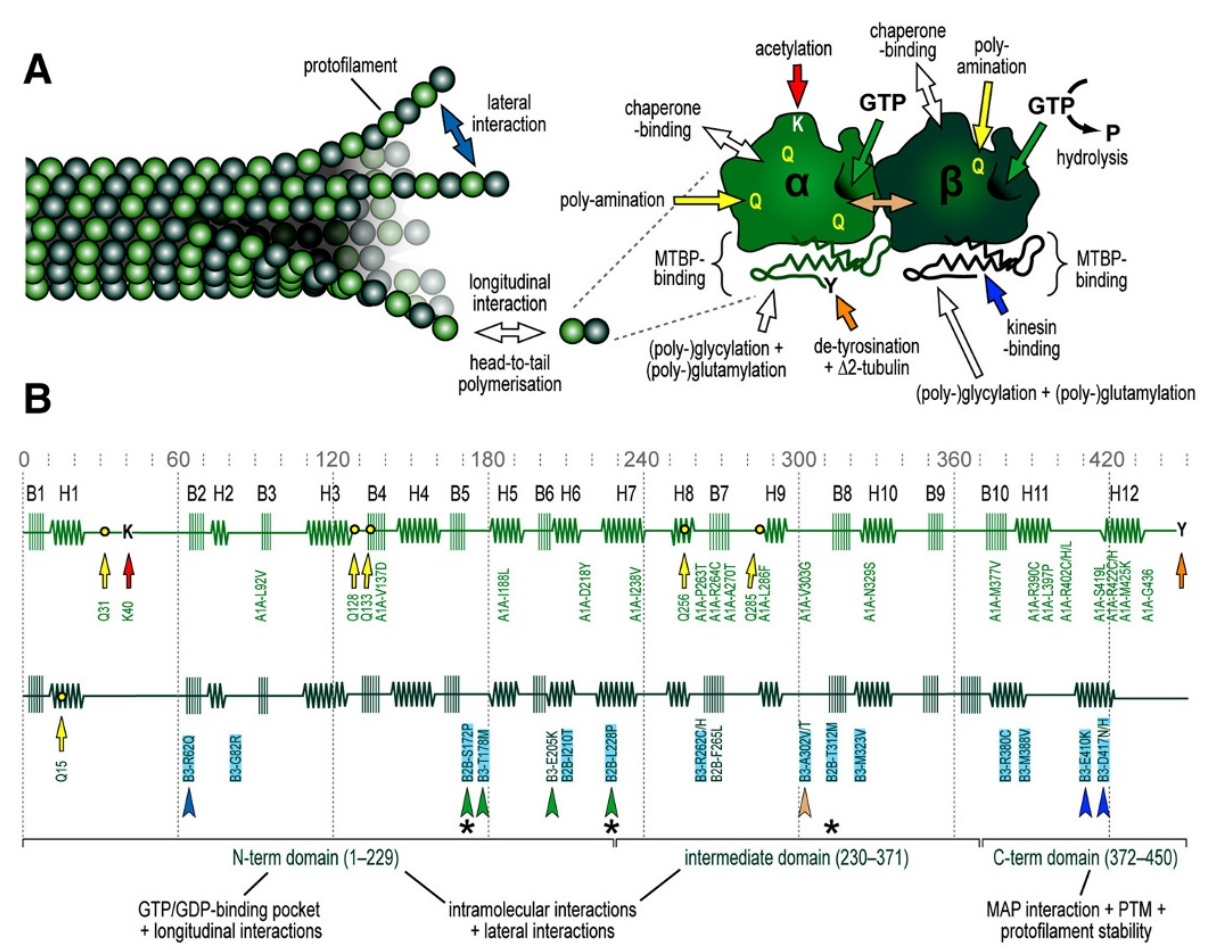

Figure 3 Structural aspects of tubulins and microtubules (MTs). (A) MTs grow through head-to-tail polymerization of a-/ß-tubulin heterodimers into protofilaments that arrange into hollow tubes through lateral interactions. The $\mathrm{a}$-and $\mathrm{B}$-tubulin monomers need to be folded properly assisted by chaperones, they heterodimerize through longitudinal interactions (peach arrow), they bind GTP (of which GTP on B-tubulin tends to undergo hydrolysis to GDP) and undergo a number of posttranslational modifications, including de-tyrosination (often followed by deglutamylation resulting in $\Delta 2$-tubulin), acetylation, poly-amination, (poly-)glycylation and (poly-)glutamylation [11]. MTBPs primarily interact with the C-terminus of tubulins which sticks out from the MT surface. (B) The secondary structure of a- and B-tubulin (color-coded as in A) showing the positions of B-sheets (B1-10) and a-helices (H1-12; image modified from [24]); the borders and principal functions of the N-terminal, intermediate and C-terminal domains of B-tubulin are indicated at the bottom and arrows indicate examples of posttranslational modification sites [11,21]. Positions of known dominant-negative mutations are shown below the two secondary structures [25]. Those mutations tested by Niwa and colleagues are highlighted in light blue, asterisks indicate those mutations that impair tubulin incorporation into MTs and blue arrowheads indicate the two charge-changing mutations in $\mathrm{H} 12$ [26].

polymerisation $[3,23,32]$. This said, $\beta 3$-tubulin can also directly interact with membrane receptors during axon growth and guidance [33]. MTBPs and +TIPs regulate further aspects of MT dynamics, such as stability and cross-linkage into bundles and MT cross-talk with F-actin, the cell cortex, organelles and transported cargo (Figure 2), and some of these activities have been shown to contribute to axon growth [3,23]. However, as argued recently [23], knowing these single molecular or subcellular mechanisms and their principal impacts on axon growth, is still far from understanding axon growth. We need to acknowledge that the various molecular mechanisms of different MTBP classes (as well as of actin- and intermediate filamentregulating proteins) integrate into one common and complex cytoskeletal machine. Taking out a single component does not bring the machinery to a halt, but may significantly change the way it works and cause phenotypes that are difficult to interpret. Therefore, we need to find strategies to decipher this machinery across its various components and to understand their functional interfaces.

\section{Axonal microtubules provide the highways for motor- driven cargo transport}

As stated above, communication of a neuronal cell body with distant segments of its axon poses a serious logistical challenge and involves long-distance axonal transport of a wide range of different cargoes including lipids, different protein classes (usually transported via cargo vesicles), organelles as large as mitochondria, but also mRNAs [34,35]. This transport occurs along the axonal MT bundles and is driven by dynein/dynactin and kinesin motor protein dimers/complexes which use pairs of motor domains to step along MTs in a 'hand-overhand' mode at a speed of $\leq 1 \mu \mathrm{m} / \mathrm{s}$ (Additional file 1: Table S1) $[34,36]$. These molecular motors require ATP as an essential energy source. The major producers of 
ATP in cells are the mitochondria, but molecular motors will only occasionally encounter mitochondria on their axonal journey. A recent report suggests that this logistical problem is solved via a system of 'on-board' ATP provision in form of the enzyme GAPDH (glyceraldehyde 3-phosphate dehydrogenase), which localizes to the cargo vesicles and contributes to the break-down of glucose from the neuronal cytosol [37].

Retrograde transport (that is, towards the cell body) is mediated by cytoplasmic dynein/dynactin which is a fairly large and multi-component protein complex adaptable to all kinds of cargos and functional tasks (Additional file 1: Table S1) $[36,38]$. Anterograde transport (that is, away from the cell body) is driven by kinesin motor proteins. Forty-five different kinesins grouped into 14 families are known in mammals, of which hetero-oligomeric type 1 and 2 as well as homodimeric type 3 kinesins are the most prevalent mediators of anterograde transport in axons (Additional file 1: Table S1) [34]. The regulation of transport speed and direction is only partly understood and involves guidance through neuronal architecture, signaling mechanisms, distinct qualities and modifications of the various motors, linkers and otherwise associated proteins, posttranslational modifications of MTs and cargo, as well as complex interactions of motors with other motors and MTBPs (Additional file 2). Understanding this transport machinery is of importance as emphasized by the many links that mutations in the various kinesin and dynein/ dynactin genes have to developmental and neurodegenerative brain disorders $[8,34,39-41]$.

\section{Charge-changing mutations in tubulins translate into roadblocks for migrating kinesins}

Also mutations in tubulin genes have been linked to human brain disorders (Figure 3) [25]. Mammalian genomes encode six classes of $\beta$-tubulins (with TUBB1, 2 and 3 being most abundant in the brain), and four classes of $\alpha$-tubulins. Given the high degree of sequence conservation between tubulins, they are likely to be able to functionally replace each other, at least partially. It seems therefore logical that most disease-linked tubulin mutations discovered to date are of dominant-negative nature, that is, mutant tubulins need to be incorporated into MTs or their polymerization machinery to alter MT functions or dynamics and impact on cellular behaviors. Some of these mutations are known or speculated to affect MT polymerization or stability interfering with protein folding and/or chaperone interactions, $\alpha$-/ $\beta$-heterodimerization, head-to-tail polymerization of dimers, the GTP-binding ability (important for MT dynamics), or the ability to establish lateral bonds between protofilaments (Figure 3) [25]. Other tubulin mutations are far less understood, but can be expected to alter interactions with different classes of MTBPs, and studies in non-neuronal cells or yeast suggested interference of some mutations with molecular motors [25,42].

Clear evidence that certain tubulin mutations affect the MT interaction with kinesins in axons has now been provided by the studies of Niwa and collaborators [26]. They transfected cultured hippocampal neurons with 14 different mutant $\beta$-tubulins (highlighted in Figure 3) and found that two of them, TUBB3 ${ }^{\mathrm{E} 410 \mathrm{~K}}$ and $\mathrm{TUBB} 3^{\mathrm{D} 417 \mathrm{H}}$, suppressed anterograde axonal cargo transport as well as the ability of type 1, 3 and 4 kinesins (that is, major players in axonal transport) to move to axon tips. Of these, the type 4 kinesin KIF21A is of particular interest: it acts as a genuine axonal transporter [43] and its mutations have been linked to type 1 congenital fibrosis of the extraocular muscles (CFEOM), a pathology that affects nerve growth to certain eye muscles [44]. The $\mathrm{TUBB}^{\mathrm{E} 410 \mathrm{~K}}$ and $\mathrm{TUBB} 3^{\mathrm{D} 417 \mathrm{H}}$ mutations cause a very similar pathology (type 3 CFEOM) [25], suggesting that these mutations functionally relate to KIF21A in vivo.

Both mutations are positioned in the $\mathrm{H} 12$ helix of $\mathrm{B}$ tubulin where they cause a negative-to-positive charge change (Figure 3, dark blue arrowheads), and a detailed structure-function analysis clearly demonstrated that the negative charge of $\mathrm{H} 12$ is crucial to properly support kinesin attachment to MTs [26]. Introduction of the E410K or D417H mutations into TUBB2 or TUBB5 caused similar transport defects, as long as these mutant tubulins were strongly expressed in neurons. However, if these mutant tubulins were prevented from assembling into MTs (by inserting a second site mutation which structurally prevents this tubulin from incorporation), their dominant-negative impact on MTs was abolished. A $10 \%$ incorporation rate of mutant tubulins into MTs was estimated to be sufficient to interfere with kinesin transport to a degree that becomes disease-relevant [26], and only brain expression of TUBB3 is high enough to achieve this degree of incorporation.

In conclusion, this work convincingly explains a molecular link between tubulins and kinesins and how their molecular properties and interactions can cause the CFEOM disorder as a common systemic outcome. Clearly, it links molecular mechanisms to cellular effects, and it nicely combines the two areas of neuronal tubulin and kinesin research in a way that expands our understanding of neuronal cytoskeletal machinery.

\section{MT motor proteins contribute to axon growth through their transport function}

Transfection of neurons in the embryonic mouse brain with $\mathrm{TUBB}^{\mathrm{E} 410 \mathrm{~K}}$ and $\mathrm{TUBB}^{\mathrm{D} 417 \mathrm{H}}$ caused reduced axon growth, and the same phenotype was observed when knocking down the type 3 kinesin KIF1B [26], suggesting that functional interactions of kinesins with MTs promote axon development. Similar observations were made for 
other axonal transport motors, in particular with loss of function of kinesin-1 and dynein/dynactin, which likewise caused reduced axon growth [45-47]. Furthermore, the loss of kinesin-3 or of dynein/dynactin components in Drosophila causes axonal aberrations, in particular of the branching and differentiation of their synaptic terminals [48-51]. This poses the important question of how the loss of motor activity affects axon growth and morphogenesis. The answer to this question is not trivial.

One obvious mechanism through which motors support axon growth is through cargo transport [52]. Thus, any growth process is in need of building materials, such as lipids, structural proteins, signaling pathway components and cell organelles which can not all be produced at the growth cone. At least part of them, or the mRNAs encoding them, have to be delivered through the axonal supply line from the cell body. This requirement is nicely illustrated by a classical experiment in which growing axons of frog retinal ganglion cells were cut off from their cell bodies in vivo; the longer the axon fragment attached to the growth cones was, the longer these growth cones survived and continued to execute their proper growth program (up to three hours), suggesting that the attached axon fragments provided a function- and life-sustaining supply pool [53]. However, aberrations of axonal transport might cause axonal growth phenotypes not only through depletion of supplies, but could trigger other pathomechanisms which secondarily impact on axon morphogenesis and differentiation. For example, a hypomorphic allele of the Drosophila Unc4 gene (kinesin-3) was recently reported to show overgrowth at the neuromuscular junction [50]. Very similar phenotypes are observed when inducing oxidative stress [54], suggesting a potential mechanism for this phenotype that can easily be tested in the fly system (Additional file 3).

\section{MT motor proteins contribute to axon growth through direct regulation of MT networks}

Also MTs are amongst the cargos transported in axons. Originally this has been considered to be slow axonal transport ( 0.1 to $3 \mathrm{~mm} /$ day) performed by KIF5/kinesin light chain (KLC) activity [52]. This view has been disputed after different experimental procedures revealed rapid bi-directional movement of short MT fragments of $\leq 10 \mu \mathrm{m}$ length [55,56]. Dynein/dynactin has been shown to mediate MT fragment movement through 'MT sliding, that is, by anchoring to long MTs or F-actin and driving MT fragments anterogradely by walking towards their minus ends (Figure 1, inset 4), and this function seems to contribute to axon growth [56-58]. It has been suggested that transported MT fragments are very stable (likely through polyamination) and could therefore promote axon growth by serving as powerful nucleation sites for new MTs along axons [10]. In agreement with this idea, blocking polyamination severely inhibits axon growth, although the underlying mechanisms have so far not been resolved [21].
This example of MT fragment transport illustrates that molecular motors not only depend on MTs for their transport functions but, vice versa, they also influence MT dynamics and behaviors, that is, they regulate the construction of the highways they will later travel on. Further examples for this have come to light. For example, type 5 (KIF11), type 6 (KIF23) and type 12 (KIF15) kinesins are best known for their MT sliding roles during mitosis. In developing axons these kinesins are growth inhibiting and seem to regulate axon growth, branching and growth cone turning through antagonizing dynein-mediated MT fragment transport and through regulating the extension of MTs in growth cones [59-62]. Furthermore, dynein and its associated factor Lis1 (Additional file 1: Table S1) have been suggested to antagonize inward-directed forces imposed by retrograde actin flow, thus helping MTs to extend into the growth cone periphery and promote axon growth [63-65]. The dynactin complex component p150 Glued plays direct roles in MT catastrophe regulation in axons [66]. Type 13 kinesins, such as KIF2A, are minus enddirected motors (not contributing to transport) which can be recruited to MT plus ends and actively disassemble them, and this function inhibits collateral branch formation of axons in vivo [67].

Also type 1 kinesins have recently been implicated in MT regulation during axon growth. Thus, the Drosophila KIF5 homolog kinesin heavy chain (KHC) was shown to drive axon initiation and transiently maintain axon growth (though to a lesser degree), even if MT polymerization or axonal transport were blocked [68]. This function did not require the transport-relevant KLC, and the authors proposed that KHC can cross-link MTs via its $\mathrm{N}$-terminal motor domains and $\mathrm{C}$-terminal MT-binding sequences. A similar mechanism was described for fly KHC as well as its frog homolog KIF5 in non-neuronal cells [69]. Notably, KIF5 is one of the first factors accumulating at axon initiation sites in mammalian neurons [70] and, if the MT sliding mechanism applies, it could similarly help MTs to push and initiate newly forming axons in mammals. Since KIF5 is also strongly enriched in growth cones [26,70], it might as well play a role in growth cone extension and/or turning, in parallel to the roles of KIF11 mentioned above [59].

In conclusion, molecular motors perform functions that clearly reach beyond mere transport roles suggesting that they display prominent mutual dependencies with MT network regulation.

\section{The roles of transport, MTs and MT motor proteins in axon maintenance}

Apart from their developmental roles, molecular motors certainly play major roles also in mature neurons. Thus, they continue to sustain the supply and communication 
lines that maintain neuronal physiology, and the transport of synaptic components, and of mitochondria to meet the high energy demand of synapses [71]. Therefore, MT motors are essential for neuronal longevity, as is also indicated by the numerous mutations in kinesin and dynein/dynactin genes which link to neuropathies and neurodegeneration $[8,34,39-41]$, as well as by the fact that the H12 loop mutations of TUBB3 link to neuropathies [25]. Intriguingly, axons in the ageing or demented brain frequently display swellings or diverticula, which are areas of looped and criss-crossed MTs posing potential transport traps $[9,72,73]$. Thus, in addition to mutations that affect the molecular motors or their binding to MTs, the turning of straight axonal MT tracks into spaghetti junctions where cargos get blocked through steric hindrance seems to be an important mechanism of interference with axonal transport, and this effect has been reproduced through mathematical modeling [74].

Since the appearance of diverticula seems to increase with ageing, research needs to be directed to the investigation of the underlying causes, that is, the study of mechanisms that maintain parallel MT bundles in healthy neurons. So far, a number of potential mechanisms were identified. Thus, structural MAPs (for example, tau and MAP1B) have long been suggested as playing an important part in maintaining MT bundles [15]. The level of cold-stable polyaminated tubulin increases in older neurons, suggesting that MT stability plays an important part [21]. Mutations affecting the MT-severing spastins cause axon swellings and transport defects in mouse models and humans [75,76]. Intermediate filaments are closely interwoven with MTs and might play roles in their ordered maintenance [22]. However, MT bundles in mature axons are not only highly stabilized structures, but they are likely to undergo constant renewal through MT polymerization [77], as is also indicated by the linkage of neuropathies to the misregulation of stathmins, powerful regulators of MT polymerization [78-81] or the tubulin chaperone Tbce $[27,82,83]$. This suggests that some mechanisms acting in development might be maintained at adult stages, as recently proposed for the actin-MT linking spectraplakins. Spectraplakins guide MTs along actin structures (potentially cortical actin; Figure 2) and lay them out into parallel bundles during axon growth, and their loss causes MT disorganization [84,85]. Analogously, loss of the spectraplakin dystonin causes MT disorganization at postnatal stages and this correlates with sensory neuropathy $[23,86]$.

Therefore, it is tempting to speculate that developmental roles of MT motors in MT organisation [45,63-66] might likewise apply at adult stages. Support for this notion is provided by KIF11 which negatively regulates axon growth during development, but also during axonal regeneration after injury in the adult brain [87]. As a further example, loss of dynein/dynactin from Drosophila neurons induces an increase in wrongly oriented minus end-out MTs in axons [88], and this is almost certain to cause transport aberrations. To explain this phenomenon, an appealing model has been put forward suggesting that dynein/dynactin might remove wrongly oriented MTs through retrograde MT transport, instead of chopping them up, like Hydra's head that would sprout new ones in their place, by using generated MT fragments as nucleation sites [56]. These few examples may only be the tip of the iceberg and more MTregulating roles of molecular motors contributing to the cellular processes underlying axon maintenance might well be discovered, but not necessarily roles and mechanisms that might be expected at this stage.

\section{Conclusions}

There is an intricate relationship between MTs, the mechanisms that drive their nucleation, (de-)polymerization, cross-linkage and modification, and the motors that use them for transport but also influence them in their regulation. Given the disease relevance of this regulatory machinery it is pivotal that we gain a better understanding of its workings. Yet, this task is challenging; it requires multidisciplinary approaches and a stronger integration of the various lines of research in the areas of tubulin regulation and MT dynamics as well as motors and transport. Importantly, we need neuronal systems in which studies of the various molecular components and functional contributions can be integrated, and this cries out for the use of simpler invertebrate model organisms such as Caenorhabditis elegans or Drosophila, which are well known for their power to work out fundamental concepts and mechanisms that can then be applied in higher animals or studies of human disease (Additional file 3) [23,89]. One essential factors that drives such research in invertebrate models is their low genetic redundancy (Additional file 1: Table S1) which facilitates functional removal of whole gene classes, alone or even in combination [90,91]. Notably, cellular models for nervous system development, injury and disorders in which the axon-relevant roles of tubulin, MT regulators and motors can be studied are already well established in Drosophila [92-94], and various examples cited in this review come from fly studies. Furthermore, attempts have already been made to simulate Drosophila axons in mathematical models [95,96], thus paving the way towards experimental assembly lines that can integrate molecular mechanisms with genetic analyses of their cellular functions and develop them into mechanistic models that will eventually be able to predict the outcome of single mutations and deliver explanations for how they cumulate in disease phenotypes. 
Naturally, the fly model has certain limitations, such as the far shorter length and life span of axons, but these differences might also provide opportunities. For example, the plekstrin homology domain-containing type 3 kinesins KIF1A and KIF1Bß and their fly homolog Unc-104 (Additional file 1: Table S1) have been implicated in transport of synaptic vesicles [52]. Whereas deletion of KIF1A or KIF1Bß function causes reduced axon growth in the mouse brain [26,97], loss of Unc104 in fly does not, although it shows deficits in the final morphology of synaptic terminals [50,51]. This might indicate functional deviation but, more likely, it reflects cellular differences where aberrant cargo transport has a greater impact in the much longer mouse axons. These possibilities are easy to test via inter-species rescue experiments and might therefore offer exciting experimental means to distinguish between roles of motors in cargo transport and their roles in MT regulation.

\section{Additional files}

Additional file 1: Table S1. Microtubule (MT)-associated motor

proteins with roles in axons [61,62,98-104].

Additional file 2: Regulation of axonal transport

$[10-12,19,34,36,71,97,98,105-118]$.

Additional file 3: Using the fruit fly Drosophila to study the cytoskeleton during axon growth $[23,85,89,91,119-122]$.

\section{Abbreviations}

EB: End binding protein; GADPH: Glyceraldehyde 3-phosphate dehydrogenase; KLC: Kinesin light chain; KHC: Kinesin heavy chain; MT: Microtubules; MTBP: Microtubule-binding protein; +TIP: Tip-interacting protein.

\section{Competing interests}

The authors declare that they have no competing interests.

\section{Acknowledgements}

I would like to thank Peter Baas, Thomas Schwarz and Natalia SánchezSoriano for their very helpful comments on this manuscript, and Carsten Janke for his constructive feedback on Figure 3. The author is funded by the BBSRC (BB/I002448/1).

Received: 2 July 2013 Accepted: 14 August 2013

Published: 8 September 2013

\section{References}

1. Debanne D, Campanac E, Bialowas A, Carlier E, Alcaraz G: Axon physiology. Physiol Rev 2011, 91:555-602.

2. Shean JF: Hannibal's mules: the logistical limitations of Hannibal's army and the Battle of Cannae, 216 BC. Zeitschrift für Alte Geschichte 1996, 45:159-187.

3. Conde $\mathrm{C}$, Caceres A: Microtubule assembly, organization and dynamics in axons and dendrites. Nat Rev Neurosci 2009, 10:319-332.

4. Bradke F, Fawcett JW, Spira ME: Assembly of a new growth cone after axotomy: the precursor to axon regeneration. Nat Rev Neurosci 2012, 13:183-193

5. Gustavsson A, Svensson M, Jacobi F, Allgulander C, Alonso J, Beghi E, Dodel R, Ekman M, Faravelli C, Fratiglioni L, et al: Cost of disorders of the brain in Europe 2010. Eur Neuropsychopharmacol 2011, 21:718-779.

6. Marner L, Nyengaard JR, Tang Y, Pakkenberg B: Marked loss of myelinated nerve fibers in the human brain with age. J Comp Neurol 2003, 462:144-152.
7. Adalbert R, Coleman MP: Axon pathology in age-related neurodegenerative disorders. Neuropathol Appl Neurobiol 2012, 39:90-108.

8. Goldstein LS: Axonal transport and neurodegenerative disease: can we see the elephant? Prog Neurobiol 2012, 99:186-190.

9. Coleman M: Axon degeneration mechanisms: commonality amid diversity. Nat Rev Neurosci 2005, 6:889-898.

10. Baas PW: Microtubule stability in the axon: new answers to an old mystery. Neuron 2013, 78:3-5.

11. Janke C, Bulinski JC: Post-translational regulation of the microtubule cytoskeleton: mechanisms and functions. Nat Rev Mol Cell Biol 2011, 12:773-786.

12. Janke $C$, Kneussel M: Tubulin post-translational modifications: encoding functions on the neuronal microtubule cytoskeleton. Trends Neurosci 2010, 33:362-372.

13. Yu W, Baas PW: Changes in microtubule number and length during axon differentiation. J Neurosci 1994, 14:2818-2829.

14. Baas PW, Lin S: Hooks and comets: the story of microtubule polarity orientation in the neuron. Dev Neurobiol 2011, 71:403-418.

15. Chilton J, Gordon-Weeks P: Role of microtubules and MAPs during neuritogenesis. In Intracellular Mechanisms for Neuritogenesis. Edited by de Curtis I. US: Springer; 2007:57-88.

16. Chapin SJ, Bulinski JC, Gundersen GG: Microtubule bundling in cells. Nature 1991, 349:24

17. Stiess M, Maghelli N, Kapitein LC, Gomis-Ruth S, Wilsch-Brauninger M, Hoogenraad CC, Tolic-Norrelykke IM, Bradke F: Axon extension occurs independently of centrosomal microtubule nucleation. Science 2010 , 327:704-707.

18. Basto R, Lau J, Vinogradova T, Gardiol A, Woods CG, Khodjakov A, Raff JW: Flies without centrioles. Cell 2006, 125:1375-1386.

19. Nakata T, Niwa S, Okada Y, Perez F, Hirokawa N: Preferential binding of a kinesin-1 motor to GTP-tubulin-rich microtubules underlies polarized vesicle transport. J Cell Biol 2011, 194:245-255.

20. Coombes CE, Yamamoto A, Kenzie MR, Odde DJ, Gardner MK: Evolving tip structures can explain age-dependent microtubule catastrophe. Curr Biol 2013, 23:1342-1348.

21. Song Y, Kirkpatrick LL, Schilling AB, Helseth DL, Chabot N, Keillor JW Johnson GV, Brady ST: Transglutaminase and polyamination of tubulin: posttranslational modification for stabilizing axonal microtubules. Neuron 2013, 78:109-123.

22. Perrot $R$, Eyer J: Neuronal intermediate filaments and neurodegenerative disorders. Brain Res Bull 2009, 80:282-295.

23. Prokop A, Beaven R, Qu Y, Sánchez-Soriano N: Using fly genetics to dissect the cytoskeletal machinery of neurons during axonal growth and maintenance. J Cell Sci 2013, 126:2331-2341.

24. Keskin O, Durell SR, Bahar I, Jernigan RL, Covell DG: Relating molecular flexibility to function: a case study of tubulin. Biophys J 2002, 83:663-680

25. Tischfield MA, Cederquist GY, Gupta ML Jr, Engle EC: Phenotypic spectrum of the tubulin-related disorders and functional implications of diseasecausing mutations. Curr Opin Genet Dev 2011, 21:286-294.

26. Niwa S, Takahashi H, Hirokawa N: (Beta)-Tubulin mutations that cause severe neuropathies disrupt axonal transport. EMBO J 2013, 32:1352-1364.

27. Schaefer MK, Schmalbruch $H$, Buhler E, Lopez C, Martin N, Guenet JL, Haase G: Progressive motor neuronopathy: a critical role of the tubulin chaperone TBCE in axonal tubulin routing from the Golgi apparatus. J Neurosci 2007, 27:8779-8789

28. Lamoureux P, Heidemann SR, Martzke NR, Miller KE: Growth and elongation within and along the axon. Dev Neurobiol 2010, 70:135-149.

29. Roossien DH, Lamoureux P, van Vactor D, Miller KE: Drosophila growth cones advance by forward translocation of the neuronal cytoskeletal meshwork in vivo. PLoS One 2013. in press.

30. Dent EW, Gupton SL, Gertler FB: The growth cone cytoskeleton in axon outgrowth and guidance. Cold Spring Harb Perspect Biol 2011, 3:a001800.

31. Lowery $L A$, van Vactor $D$ : The trip of the tip: understanding the growth cone machinery. Nat Rev Mol Cell Biol 2009, 10:332-343.

32. Akhmanova A, Steinmetz MO: Tracking the ends: a dynamic protein network controls the fate of microtubule tips. Nat Rev Mol Cell Biol 2008, 9:309-322.

33. Qu C, Dwyer T, Shao Q, Yang T, Huang H, Liu G: Direct binding of TUBB3 with DCC couples netrin-1 signaling to intracellular microtubule dynamics in axon outgrowth and guidance. J Cell Sci 2013, 126:3070-3081. 
34. Hirokawa N, Niwa S, Tanaka Y: Molecular motors in neurons: transport mechanisms and roles in brain function, development, and disease. Neuron 2010, 68:610-638.

35. Twelvetrees A, Hendricks AG, Holzbaur ELF: SnapShot: axonal transport. Cell 2012, 149:950-e951.

36. Allan VJ: Cytoplasmic dynein. Biochem Soc Trans 2011, 39:1169-1178

37. Zala D, Hinckelmann M-V, Yu H, da Cunha L, Marcel M, Liot G, Cordelières FP, Marco S, Saudou F: Vesicular glycolysis provides on-board energy for fast axonal transport. Cell 2013, 152:479-491.

38. Raaijmakers JA, Tanenbaum ME, Medema RH: Systematic dissection of dynein regulators in mitosis. J Cell Biol 2013, 201:201-215.

39. De Vos KJ, Grierson AJ, Ackerley S, Miller CC: Role of axonal transport in neurodegenerative diseases. Annu Rev Neurosci 2008, 31:151-173.

40. Millecamps S, Julien JP: Axonal transport deficits and neurodegenerative diseases. Nat Rev Neurosci 2013, 14:161-176.

41. Sheng ZH, Cai Q: Mitochondrial transport in neurons: impact on synaptic homeostasis and neurodegeneration. Nat Rev Neurosci 2012, 13:77-93.

42. Tischfield MA, Baris HN, Wu C, Rudolph G, Van Maldergem L, He W, Chan WM, Andrews C, Demer JL, Robertson RL, et al: Human TUBB3 mutations perturb microtubule dynamics, kinesin interactions, and axon guidance. Cell 2010, 140:74-87.

43. Lee KH, Lee JS, Lee D, Seog DH, Lytton J, Ho WK, Lee SH: KIF21A-mediated axonal transport and selective endocytosis underlie the polarized targeting of NCKX2. J Neurosci 2012, 32:4102-4117.

44. Yamada K, Andrews C, Chan WM, McKeown CA, Magli A, de Berardinis T, Loewenstein A, Lazar M, O'Keefe M, Letson R, et al: Heterozygous mutations of the kinesin KIF21A in congenital fibrosis of the extraocular muscles type 1 (CFEOM1). Nat Genet 2003, 35:318-321.

45. Ahmad FJ, He Y, Myers KA, Hasaka TP, Francis F, Black MM, Baas PW: Effects of dynactin disruption and dynein depletion on axonal microtubules. Traffic 2006, 7:524-537

46. Abe TK, Honda T, Takei K, Mikoshiba K, Hoffman-Kim D, Jay DG, Kuwano R: Dynactin is essential for growth cone advance. Biochem Biophys Res Commun 2008, 372:418-422.

47. Ferreira A, Niclas J, Vale RD, Banker G, Kosik KS: Suppression of kinesin expression in cultured hippocampal neurons using antisense oligonucleotides. J Cell Biol 1992, 117:595-606.

48. Eaton BA, Fetter RD, Davis GW: Dynactin is necessary for synapse stabilization. Neuron 2002, 34:729-741.

49. Murphey RK, Caruccio PC, Getzinger M, Westgate PJ, Phillis RW: Dyneindynactin function and sensory axon growth during Drosophila metamorphosis: a role for retrograde motors. Dev Biol 1999, 209:86-97.

50. Kern JV, Zhang W, Kramer S, Brenman JE, Rasse TM: The Kinesin-3, Unc-104 regulates dendrite morphogenesis and synaptic development in Drosophila. Genetics 2013. doi:10.1534/genetics.1113.151639.

51. Pack-Chung E, Kurshan PT, Dickman DK, Schwarz TL: A Drosophila kinesin required for synaptic bouton formation and synaptic vesicle transport. Nat Neurosci 2007, 10:980-989.

52. Hirokawa N, Noda Y: Intracellular transport and kinesin superfamily proteins, KIFs: structure, function, and dynamics. Physiol Rev 2008, 88:1089-1118.

53. Harris WA, Holt CE, Bonhoeffer F: Retinal axons with and without their somata, growing to and arborizing in the tectum of Xenopus embryos: a time-lapse video study of single fibers in vivo. Development 1987, 101:123-133.

54. Milton VJ, Jarrett HE, Gowers K, Chalak S, Briggs L, Robinson IM, Sweeney ST: Oxidative stress induces overgrowth of the Drosophila neuromuscular junction. Proc Natl Acad Sci U S A 2011, 108:17521-17526.

55. Wang $L$, Brown A: Rapid movement of microtubules in axons. Curr Biol 2002, 12:1496-1501.

56. Baas PW, Mozgova Ol: A novel role for retrograde transport of microtubules in the axon. Cytoskeleton (Hoboken) 2012, 69:416-425.

57. Myers KA, He Y, Hasaka TP, Baas PW: Microtubule transport in the axon: re-thinking a potential role for the actin cytoskeleton. Neuroscientist 2006, 12:107-118.

58. Baas PW, Vidya NC, Myers KA: Axonal transport of microtubules: the long and short of it. Traffic 2006, 7:490-498.

59. Nadar VC, Lin S, Baas PW: Microtubule redistribution in growth cones elicited by focal inactivation of kinesin-5. J Neurosci 2012, 32:5783-5794.

60. Myers KA, Baas PW: Kinesin-5 regulates the growth of the axon by acting as a brake on its microtubule array. J Cell Biol 2007, 178:1081-1091.
61. Lin S, Liu M, Mozgova Ol, Yu W, Baas PW: Mitotic motors coregulate microtubule patterns in axons and dendrites. J Neurosci 2012, 32:14033-14049.

62. Liu M, Nadar VC, Kozielski F, Kozlowska M, Yu W, Baas PW: Kinesin-12, a mitotic microtubule-associated motor protein, impacts axonal growth, navigation, and branching. J Neurosci 2010, 30:14896-14906.

63. Grabham PW, Seale GE, Bennecib M, Goldberg DJ, Vallee RB: Cytoplasmic dynein and LIS1 are required for microtubule advance during growth cone remodeling and fast axonal outgrowth. J Neurosci 2007, 27:5823-5834.

64. Myers KA, Tint I, Nadar CV, He Y, Black MM, Baas PW: Antagonistic forces generated by cytoplasmic dynein and myosin-Il during growth cone turning and axonal retraction. Traffic 2006, 7:1333-1351.

65. Dehmelt L, Nalbant P, Steffen W, Halpain S: A microtubule-based, dynein-dependent force induces local cell protrusions: implications for neurite initiation. Brain Cell Biol 2006, 35:39-56.

66. Lazarus JE, Moughamian AJ, Tokito MK, Holzbaur EL: Dynactin subunit p150(Glued) is a neuron-specific anti-catastrophe factor. PLOS Biol 2013, 11:e1001611.

67. Hirokawa N, Takemura R: Molecular motors in neuronal development, intracellular transport and diseases. Curr Opin Neurobiol 2004, $14: 564-573$

68. Lu W, Fox P, Lakonishok M, Davidson MW, Gelfand VI: Initial neurite outgrowth in Drosophila neurons is driven by Kinesin-powered microtubule sliding. Curr Biol 2013, 23:1018-1023.

69. Jolly AL, Kim H, Srinivasan D, Lakonishok M, Larson AG, Gelfand VI: Kinesin-1 heavy chain mediates microtubule sliding to drive changes in cell shape. Proc Natl Acad Sci U S A 2010, 107:12151-12156.

70. Jacobson C, Schnapp B, Banker GA: A change in the selective translocation of the kinesin-1 motor domain marks the initial specification of the axon. Neuron 2006, 49:797-804.

71. Schwarz TL: Mitochondrial trafficking in neurons. Cold Spring Harb Perspect Biol 2013, 5:a011304

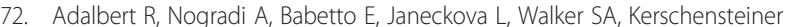
M, Misgeld T, Coleman MP: Severely dystrophic axons at amyloid plaques remain continuous and connected to viable cell bodies. Brain 2009, 132:402-416.

73. Fiala JC, Feinberg $M$, Peters $A$, Barbas $\mathrm{H}$ : Mitochondrial degeneration in dystrophic neurites of senile plaques may lead to extracellular deposition of fine filaments. Brain Struct Funct 2007, 212:195-207.

74. Kuznetsov AV, Avramenko AA: A macroscopic model of traffic jams in axons. Math Biosci 2009, 218:142-152.

75. Kasher PR, De Vos KJ, Wharton SB, Manser C, Bennett EJ, Bingley M, Wood JD, Milner R, McDermott CJ, Miller CC, et al: Direct evidence for axonal transport defects in a novel mouse model of mutant spastin-induced hereditary spastic paraplegia (HSP) and human HSP patients. J Neurochem 2009, 110:34-44.

76. Tarrade A, Fassier C, Courageot S, Charvin D, Vitte J, Peris L, Thorel A Mouisel E, Fonknechten $N$, Roblot $N$, et al: A mutation of spastin is responsible for swellings and impairment of transport in a region of axon characterized by changes in microtubule composition. Hum Mol Genet 2006, 15:3544-3558.

77. Kollins KM, Bell RL, Butts M, Withers GS: Dendrites differ from axons in patterns of microtubule stability and polymerization during development. Neural Dev 2009, 4:26.

78. Cheishvili D, Maayan C, Cohen-Kupiec R, Lefler S, Weil M, Ast G, Razin A: IKAP/Elp1 involvement in cytoskeleton regulation and implication for familial dysautonomia. Hum Mol Genet 2011, 20:1585-1594.

79. Duncan JE, Lytle NK, Zuniga A, Goldstein LS: The microtubule regulatory protein Stathmin is required to maintain the integrity of axonal microtubules in Drosophila. PLoS One 2013, 8:e68324.

80. Wen HL, Lin YT, Ting CH, Lin-Chao S, Li H, Hsieh-Li HM: Stathmin, a microtubule-destabilizing protein, is dysregulated in spinal muscular atrophy. Hum Mol Genet 2010, 19:1766-1778.

81. Liedtke W, Leman EE, Fyffe RE, Raine CS, Schubart UK: Stathmin-deficient mice develop an age-dependent axonopathy of the central and peripheral nervous systems. Am J Pathol 2002, 160:469-480.

82. Bommel H, Xie G, Rossoll W, Wiese S, Jablonka S, Boehm T, Sendtner M: Missense mutation in the tubulin-specific chaperone $E$ (Tbce) gene in the mouse mutant progressive motor neuronopathy, a model of human motor neuron disease. J Cell Biol 2002, 159:563-569. 
83. Martin N, Jaubert J, Gounon P, Salido E, Haase G, Szatanik M, Guenet JL: A missense mutation in Tbce causes progressive motor neuronopathy in mice. Nat Genet 2002, 32:443-447.

84. Alves-Silva J, Sánchez-Soriano N, Beaven R, Klein M, Parkin J, Millard T, Bellen H, Venken KJT, Ballestrem C, Kammerer RA, Prokop A: Spectraplakins promote microtubule-mediated axonal growth by functioning as structural microtubule-associated proteins and EB1-dependent +TIPs (tip interacting proteins). J Neurosci 2012, 32:9143-9158.

85. Sánchez-Soriano N, Travis M, Dajas-Bailador F, Goncalves-Pimentel C, Whitmarsh AJ, Prokop A: Mouse ACF7 and Drosophila Short stop modulate filopodia formation and microtubule organization during neuronal growth. J Cell Sci 2009, 122:2534-2542.

86. Edvardson S, Cinnamon Y, Jalas C, Shaag A, Maayan C, Axelrod FB, Elpeleg $\mathrm{O}$ : Hereditary sensory autonomic neuropathy caused by a mutation in dystonin. Ann Neurol 2012, 71:569-572.

87. Lin S, Liu M, Son YJ, Himes TB, Snow DM, Yu W, Baas PW: Inhibition of Kinesin-5, a microtubule-based motor protein, as a strategy for enhancing regeneration of adult axons. Traffic 2011, 12:269-286.

88. Zheng Y, Wildonger J, Ye B, Zhang Y, Kita A, Younger SH, Zimmerman S, Jan $L Y$, Jan $Y N$ : Dynein is required for polarized dendritic transport and uniform microtubule orientation in axons. Nat Cell Biol 2008, 10:1172-1180.

89. Bellen HJ, Tong C, Tsuda H: 100 years of Drosophila research and its impact on vertebrate neuroscience: a history lesson for the future. Nat Rev Neurosci 2010, 11:514-522.

90. Koper A, Schenck A, Prokop A: Analysis of adhesion molecules and basement membrane contributions to synaptic adhesion at the Drosophila embryonic NMJ. PLoS One 2012, 7:e36339.

91. Gonçalves-Pimentel C, Gombos R, Mihály J, Sánchez-Soriano N, Prokop A Dissecting regulatory networks of filopodia formation in a Drosophila growth cone model. PLOS ONE 2011, 6:e18340.

92. Gistelinck M, Lambert JC, Callaerts P, Dermaut B, Dourlen P: Drosophila models of tauopathies: what have we learned? Int J Alzheimers Dis 2012, 2012:970980.

93. Fang $Y$, Bonini NM: Axon degeneration and regeneration: insights from Drosophila models of nerve injury. Annu Rev Cell Dev Biol 2012, 28:575-597.

94. Jaiswal M, Sandoval H, Zhang K, Bayat V, Bellen HJ: Probing mechanisms that underlie human neurodegenerative disease in Drosophila. Annu Rev Genet 2012, 46:371-396.

95. Kuznetsov AV: Modeling active transport in Drosophila unipolar motor neurons. Comput Methods Biomech Biomed Engin 2011, 14:1117-1131.

96. Kuznetsov AV: Method of modeling intracellular transport in branching neurites: application to axons and dendrites of Drosophila sensory neurons. Comput Methods Biomech Biomed Engin 2011, 14:239-251.

97. Liu JS, Schubert CR, Fu X, Fourniol FJ, Jaiswal JK, Houdusse A, Stultz CM Moores CA, Walsh CA: Molecular basis for specific regulation of neuronal kinesin-3 motors by doublecortin family proteins. Mol Cell 2012, 47:707-721.

98. Hirokawa N, Takemura R: Molecular motors and mechanisms of directional transport in neurons. Nat Rev Neurosci 2005, 6:201-214.

99. Kim AJ, Endow SA: A kinesin family tree. J Cell Sci 2000, 113(Pt 21):3681-3682.

100. Huo L, Yue Y, Ren J, Yu J, Liu J, Yu Y, Ye F, Xu T, Zhang M, Feng W: The CC1-FHA tandem as a central hub for controlling the dimerization and activation of kinesin-3 KIF1A. Structure 2012, 20:1550-1561.

101. Acar S, Carlson DB, Budamagunta MS, Yarov-Yarovoy V, Correia JJ, Niñonuevo MR, Jia W, Tao L, Leary JA, Voss JC, et al: The bipolar assembly domain of the mitotic motor kinesin-5. Nat Commun 2013, 4:1343.

102. McQuilton P, St Pierre SE, Thurmond J: FlyBase 101 - the basics of navigating FlyBase. Nucleic Acids Res 2012, 40:D706-D714.

103. Hummel T, Schimmelpfeng K, Klambt C: Commissure formation in the embryonic CNS of Drosophila. I. Identification of the required gene functions. Dev Biol 1999, 209:381-398.

104. Eckley DM, Schroer TA: Interactions between the evolutionarily conserved, actin-related protein, Arp11, actin, and Arp1. Mol Biol Cell 2003, 14:2645-2654.

105. Franker MA, Hoogenraad CC: Microtubule-based transport - basic mechanisms, traffic rules and role in neurological pathogenesis. J Cell Sci 2013, 126:2319-2329.

106. Wu YE, Huo L, Maeder Cl, Feng W, Shen K: The balance between capture and dissociation of presynaptic proteins controls the spatial distribution of synapses. Neuron 2013, 78:994-1011.
107. Fu MM, Holzbaur EL: JIP1 regulates the directionality of APP axonal transport by coordinating kinesin and dynein motors. J Cell Biol 2013, 202:495-508.

108. Xu K, Zhong G, Zhuang X: Actin, Spectrin, and associated proteins form a periodic cytoskeletal structure in axons. Science 2013, 339:452-456.

109. Rai AK, Rai A, Ramaiya AJ, Jha R, Mallik R: Molecular adaptations allow dynein to generate large collective forces inside cells. Cell 2013, 152:172-182.

110. Martin M, lyadurai SJ, Gassman A, Gindhart JG Jr, Hays TS, Saxton WM: Cytoplasmic dynein, the dynactin complex, and kinesin are interdependent and essential for fast axonal transport. Mol Biol Cell 1999, 10:3717-3728

111. Lo KY, Kuzmin A, Unger SM, Petersen JD, Silverman MA: KIF1A is the primary anterograde motor protein required for the axonal transport of dense-core vesicles in cultured hippocampal neurons. Neurosci Lett 2011, 491:168-173.

112. Jean DC, Baas PW, Black MM: A novel role for doublecortin and doublecortin-like kinase in regulating growth cone microtubules. Hum Mol Genet 2012, 21:5511-5527.

113. Sung HH, Telley IA, Papadaki P, Ephrussi A, Surrey T, Rørth P: Drosophila Ensconsin promotes productive recruitment of Kinesin-1 to microtubules. Dev Cell 2008, 15:866-876.

114. Metzger T, Gache V, Xu M, Cadot B, Folker ES, Richardson BE, Gomes ER, Baylies MK: MAP and kinesin-dependent nuclear positioning is required for skeletal muscle function. Nature 2012, 484:120-124.

115. Ebneth A, Godemann R, Stamer K, Illenberger S, Trinczek B, Mandelkow E: Overexpression of tau protein inhibits kinesin-dependent trafficking of vesicles, mitochondria, and endoplasmic reticulum: implications for Alzheimer's disease. J Cell Biol 1998, 143:777-794.

116. McVicker DP, Chrin LR, Berger CL: The nucleotide-binding state of microtubules modulates kinesin processivity and the ability of Tau to inhibit kinesin-mediated transport. J Biol Chem 2011, 286:42873-42880.

117. LaPointe NE, Morfini G, Pigino G, Gaisina IN, Kozikowski AP, Binder LI, Brady ST: The amino terminus of tau inhibits kinesin-dependent axonal transport: implications for filament toxicity. J Neurosci Res 2009, 87:440-451.

118. Falzone TL, Gunawardena S, McCleary D, Reis GF, Goldstein LS: Kinesin-1 transport reductions enhance human tau hyperphosphorylation, aggregation and neurodegeneration in animal models of tauopathies. Hum Mol Genet 2010, 19:4399-4408.

119. Roote J, Prokop A: How to design a genetic mating scheme: a basic training package for Drosophila genetics. G3 (Bethesda) 2013, 3:353-358.

120. Sánchez-Soriano N, Tear G, Whitington P, Prokop A: Drosophila as a genetic and cellular model for studies on axonal growth. Neural Develop 2007, 2:9.

121. Sánchez-Soriano N, Gonçalves-Pimentel C, Beaven R, Haessler U, Ofner L, Ballestrem C, Prokop A: Drosophila growth cones: a genetically tractable platform for the analysis of axonal growth dynamics. Dev Neurobio/ 2010, 70:58-71.

122. Prokop A, Küppers-Munther B, Sánchez-Soriano N: Using primary neuron cultures of Drosophila to analyze neuronal circuit formation and function. In The Making and Un-making of Neuronal Circuits in Drosophila. Volume 69. Edited by Hassan BA. New York: Humana Press; 2012:225-247. Walz W (Series Editor): Neuromethods).

doi:10.1186/1749-8104-8-17

Cite this article as: Prokop: The intricate relationship between microtubules and their associated motor proteins during axon growth and maintenance. Neural Development 2013 8:17. 